\title{
Influence of Root Knot Nematode (Meloidogyne spp.) on Phenolic Acid Profile in Root of Tomato (Solanum lycopersicum L.)
}

\author{
Vyomesh S. Patel $^{1 *}$, Y.M. Shukla ${ }^{2}$ and J.J. Dhruve ${ }^{1}$ \\ ${ }^{1}$ Department of Biochemistry, BACA, Anand Agricultural University, \\ Anand-388110, Gujarat, India \\ ${ }^{2}$ College of Agriculture, Anand Agricultural University, Vaso-387380, Gujarat, India \\ *Corresponding author
}

\begin{tabular}{|c|}
\hline Keywords \\
\hline $\begin{array}{l}\text { Chlorogenic acid, } \\
\text { Meloidogyne } \\
\text { incognita, Phenolic } \\
\text { acid, Root knot } \\
\text { nematode, Sinapic } \\
\text { acid, Solanum } \\
\text { lycopersicum, } \\
\text { UPLC. }\end{array}$ \\
\hline Article Info \\
\hline $\begin{array}{l}\text { Accepted: } \\
10 \text { September } 2017 \\
\text { Available Online: } \\
10 \text { October } 2017\end{array}$ \\
\hline
\end{tabular}

\section{Introduction}

Tomato (Solanum lycopersicum L.) is one of the most popular vegetable crops worldwide, owing to its high nutritive value and diversified use. Plant parasitic nematodes are important pests of tomato and cause huge economic losses (Bird and Kaloshian, 2003). India is the second largest tomato growing country having cultivation area of 8.8 lakh ha with production of $18.23 \mathrm{mmt}$ with productivity $20.72 \mathrm{mt} / \mathrm{ha}$ during 2014-15 (NHB Database, 2016). Tomato is affected by various disease caused mainly by fungi, bacteria and nematodes. Root-knot nematodes (Meloidogyne spp.) are phytopathogenic 
obligate endoparasites nematodes that infect many plant species and cause serious damage to agricultural crops per year (Abad et al., 2008). The occurrence and metabolism of phenolic substances in plants, in response to injury or invasion by pathogens, such as fungi, bacteria and viruses, have been studied extensively (Hung and Rohde, 1973). However, Krishnappa (1985) reported from India that $M$. incognita and $M$. javanica have the widest host range infecting more than 232 and 114 genera of plants respectively. Various scientists (Patel et al., 1986 and Prasad 1960) have reported that $82.5 \%$ plants of tomato, brinjal and okra infested with $M$. incognita and $M$. javanica and parasitization of the wheat roots by M. javanica in Gujarat. During biotic stress condition, plant under goes various molecular changes to cope up with the altered environment. One such change was in phenylpropanoid metabolism which involved in the production of phenolics and phytoalexins that prevent establishment of the pathogen (Mariutto et al., 2011). Till date very limited information was available for tomato-root knot nematode infection on the biochemical and molecular changes especially phenolic acid profile of plants. This information may help us to develop new strategies for breeding of resistant line of tomato for root knot nematode infection.

\section{Materials and Methods}

The present investigation was carried out at Department of Biochemistry and Department of Nematology; B. A. College of Agriculture; Anand Agricultural University; Anand during 2015 to 2017. Two tomato cultivars AT 3 (susceptible) and SL 120 (resistant) were grown under normal (control) and disease (inoculated with $\mathrm{J} 2$ stage larvae) condition in pots. Tomato seedlings were infected at the stage of three true leaves with inoculum density of $3000 \mathrm{~J}_{2}$ stage larvae/ plant at the base of each plant in small holes. 45 days after infection, the tomato plants were carefully removed and the root systems washed free of soil and were used for biochemical analysis. The treatment details are as follows.

$\mathrm{T}_{1}=$ control (seedlings of AT 3 grown in uninoculated sterile soil)

$\mathrm{T}_{2}=$ Disease (seedlings AT 3 grown in soil inoculated with Root knot nematodes (3000 $\mathrm{J}_{2}$ stage larvae / plant).

$\mathrm{T}_{3}=$ control (seedlings of SL 120 grown in uninoculated sterile soil)

$\mathrm{T}_{4}=$ Disease (seedlings of SL 120 grown in soil inoculated with Root knot nematodes (3000 $\mathrm{J}_{2}$ stage larvae / plant).

Moisture content was estimated as per A. O. A. C. (2000) using randomly selected roots from each treatment. Total phenol was estimated by the method described by Bray and Thorpe (1954) with some modifications.

One gram of roots sample was homogenized in $80 \%$ methanol using mortar and pestle and final volume was made to $10 \mathrm{ml}$. The content was refluxed for two hour on boiling water bath at $65^{\circ} \mathrm{C}$. Supernatant was collected and residue was re-extracted twice with $80 \%$ methanol. All supernatant were combined and final volume was made to $25 \mathrm{ml}$. The extract was used for the assay of total phenol.

\section{Phenol profiling by Ultra Performance Liquid Chromatography (UPLC)}

Precisely, known amount $(1 \mathrm{~g})$ of each sample was homogenized in $80 \%$ methanol. The extracted sample was concentrated with diethyl ether, filtered through $0.45 \mu$ PVDF membrane filter and filtrate was used for further analysis. The analysis was performed using Waters system consisted of quaternary 
pump, photodiode array detector and an auto sampler. A reverse phase AccQ Tag Ultra BEH C18 column $(1.7 \mu \mathrm{m}, 2.1 \mathrm{~mm} \times 100 \mathrm{~mm})$ was used with a gradient of $0.1 \%$ Formic acid (Solvent A) and 95\% Methanol (Solvent B). The chromatographic separations were obtained using multi steps gradient system (Table 1) and a column and auto sampler temperature were held at $55{ }^{\circ} \mathrm{C}$ and $5{ }^{\circ} \mathrm{C}$, respectively. PDA spectra were measured over a wavelength range of $200-400 \mathrm{~nm}$ and detection set at $280 \mathrm{~nm}$. Limit of detection (LOD) and limit of quantification (LOQ) were determined by injecting a series of dilute solutions with known concentrations on the basis of signal to noise ratio equal to around 3 and 10, respectively. The linearity standard curves were obtained by running three injections of standards mixture at 2, 5, 10, 25 and 50 ppm (Figure 4). Empower 3 software was used for data acquisition and analysis. Peaks were identified by comparing retention times of phenolic standards and peak area was calculated automatically by integrating the peak with apex type.

\section{Results and Discussion}

Moisture plays an important role in seed germination and emergence. The analysis of seed revealed a significant $(\mathrm{p}<0.05)$ variation $(82.06-90.46 \%)$ in root moisture content among all treatments (Fig. 1). Significantly the lowest moisture content was recorded with treatment $T_{2}$, while the highest moisture content was recorded with treatment $\mathrm{T}_{3}$. There was reduction of moisture content during transition from control to disease environment. It was also found that the rate of reduction of moisture content was higher i.e. $5.61 \%$ between treatment $\mathrm{T}_{1}$ and $\mathrm{T}_{2}$, while in case of the reduction rate of moisture content was found $1.0 \%$ between treatment $\mathrm{T}_{3}$ and $\mathrm{T}_{4}$. These results are in agreement with the results observed by Dawson and Weste (1984).

The data on phenol content of tomato roots were presented in Figure 2. The maximum and minimum content of phenol was recorded for $\mathrm{T}_{1}(0.1 \%)$ and $\mathrm{T}_{4}(0.36 \%)$, respectively. The total phenol content was higher in disease condition as compared to control. There was rise in total phenol content in both susceptible and resistant cultivar during transition from control to disease environment. There was a significant rise in total phenol content in susceptible cultivar AT 3 under disease condition $(0.26 \%)$ i.e. $\mathrm{T}_{2}$ as compared to the AT 3 (control) under normal condition $(0.1 \%)$ i.e. $\mathrm{T}_{1}$. The results indicate that high phenolic may provide a source of dietary anti-oxidants. The phenolic compounds may contribute directly to the antioxidant action; therefore, it is necessary to investigate total phenolic content (Syeda et al., 2008). These results are in agreement with the results observed by Shreenivasa et al., 2011 and Choudhary et al., 2013.

Table.1 Gradient system of mobile phase used for phenol analysis

\begin{tabular}{|c|c|c|c|c|}
\hline Time (min) & Flow Rate (ml/min) & $\mathbf{\% A}$ & $\mathbf{\% B}$ & Curve \\
\hline Initial & 0.5 & 99.0 & 1.0 & Initial \\
\hline 0.50 & 0.5 & 99.0 & 1.0 & 6 \\
\hline 3.20 & 0.5 & 75.0 & 25.0 & 6 \\
\hline 3.50 & 0.5 & 70.0 & 30.0 & 6 \\
\hline 4.00 & 0.5 & 65.0 & 35.0 & 6 \\
\hline 5.00 & 0.5 & 30.0 & 70.0 & 6 \\
\hline 5.50 & 0.5 & 30.0 & 70.0 & 6 \\
\hline 7.00 & 0.5 & 99.0 & 1.0 & 6 \\
\hline 7.50 & 0.5 & 99.0 & 1.0 & 6 \\
\hline
\end{tabular}

Where; $\mathrm{A}=0.1 \%$ Formic Acid; $\mathrm{B}=95 \%$ Methanol 
Fig.1 Moisture content of roots of tomato cultivars

\section{Moisture Content (\%)}

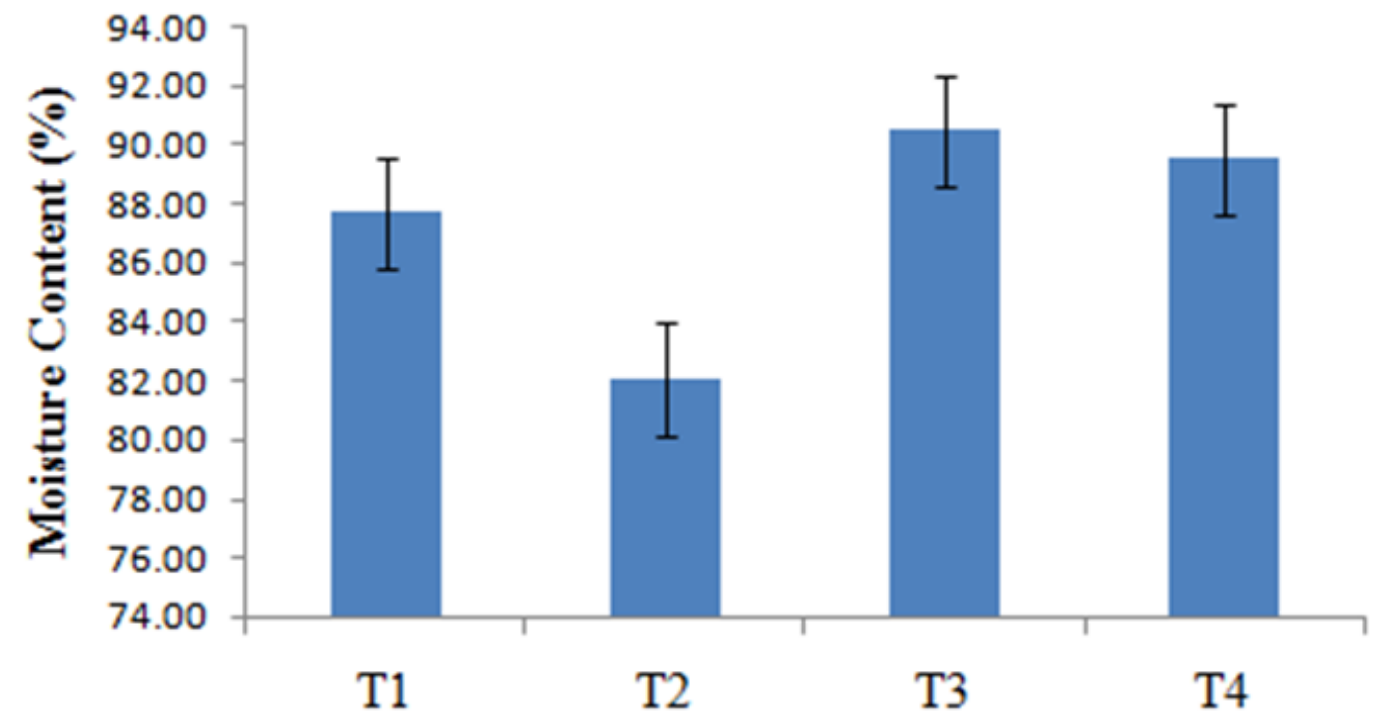

$\mathrm{T}_{1}$ : AT 3 (Control); $\mathrm{T}_{2}$ : AT 3 (Disease); $\mathrm{T}_{3}$ : SL 120 (Control); $\mathrm{T}_{4}$ : SL 120 (Disease)

Fig.2 Total phenol content of roots of tomato cultivars

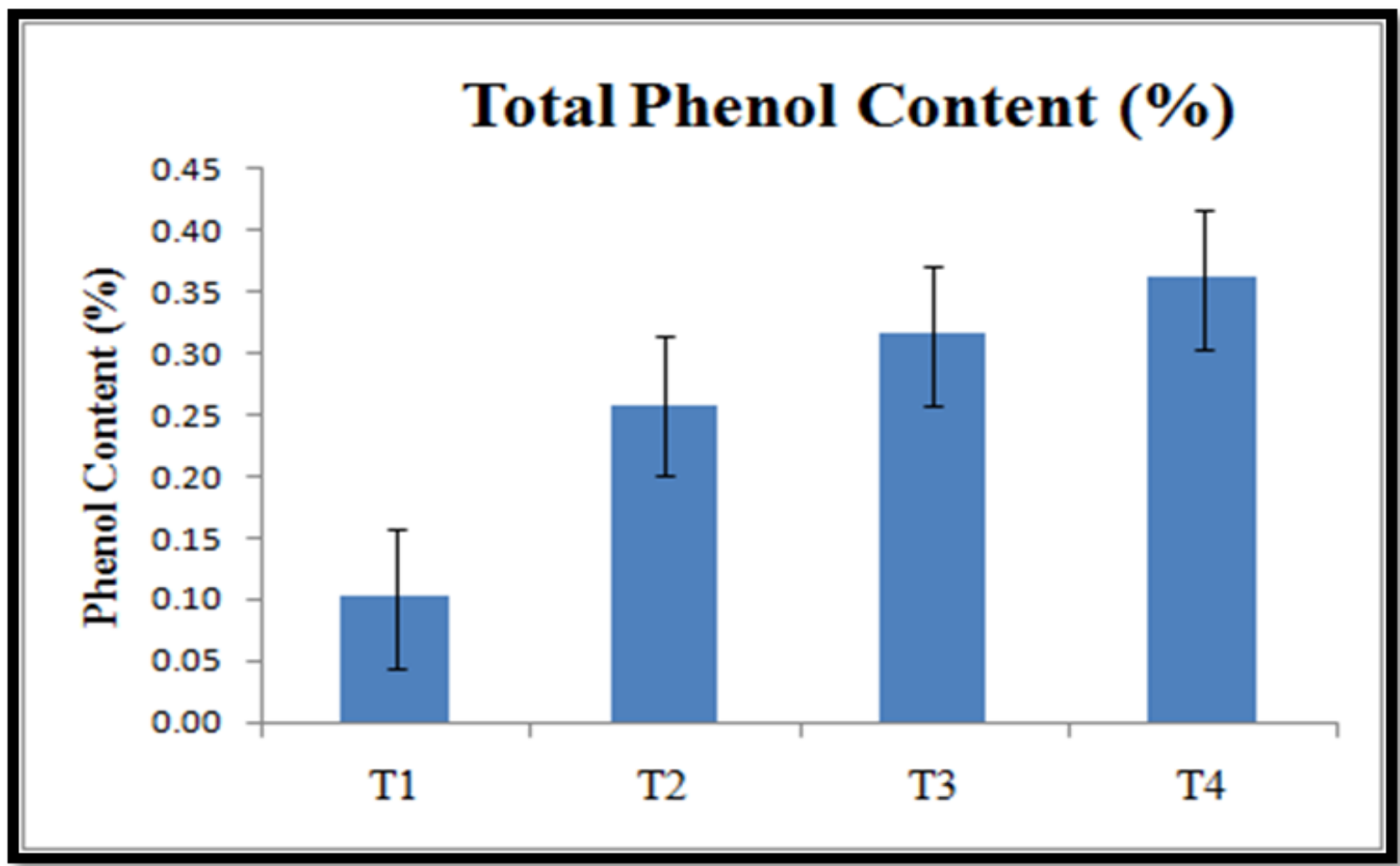

$\mathrm{T}_{1}$ : AT 3 (Control); $\mathrm{T}_{2}$ : AT 3 (Disease); $\mathrm{T}_{3}$ : SL 120 (Control); $\mathrm{T}_{4}:$ SL 120 (Disease) 
Fig.3 Phenolic acids profile by UPLC in roots of tomato cultivars

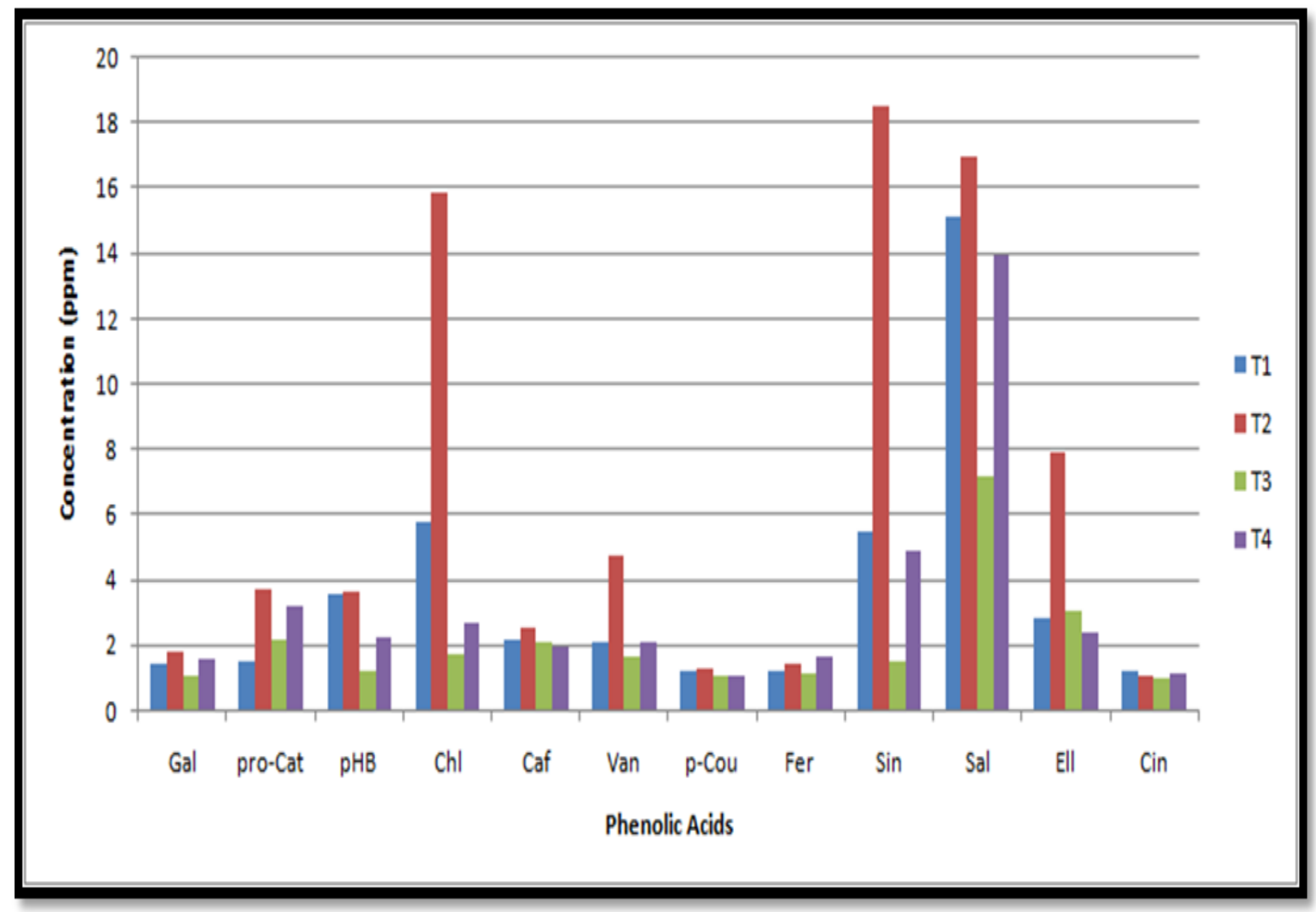

$\mathrm{T}_{1}$ : AT 3 (Control); $\mathrm{T}_{2}$ : AT 3 (Disease); $\mathrm{T}_{3}$ : SL 120 (Control); $\mathrm{T}_{4}$ : SL 120 (Disease) 
Fig.4 UPLC overlay chromatogram of phenolic acid standard mixture

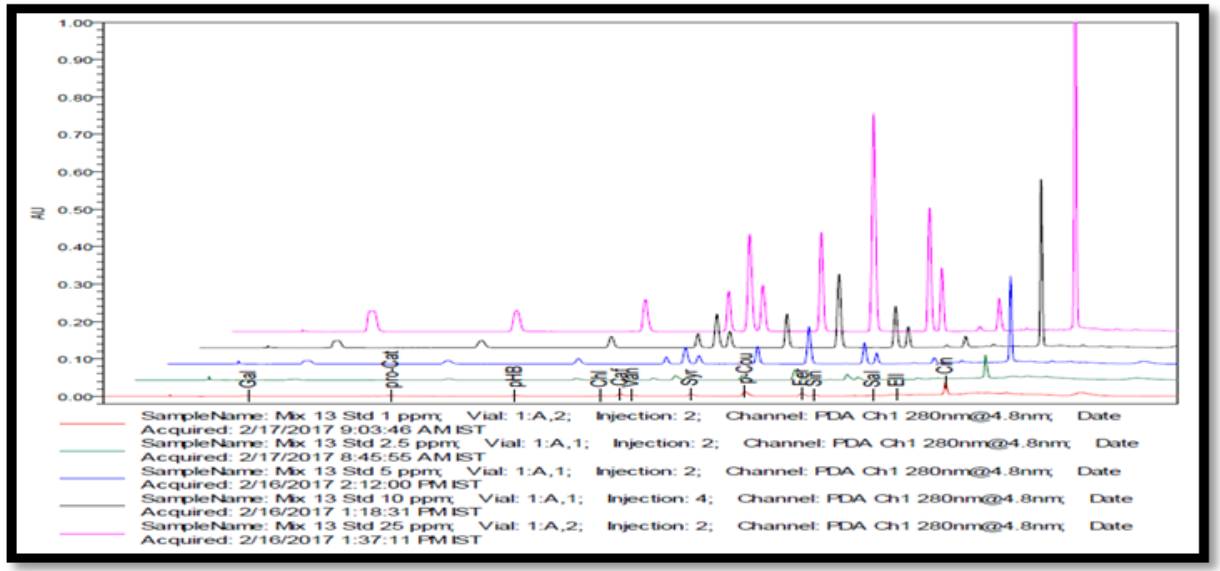

Fig.5 UPLC chromatogram of phenolic acid for $\mathrm{T}_{1}$ i.e. AT - 3 (Control)

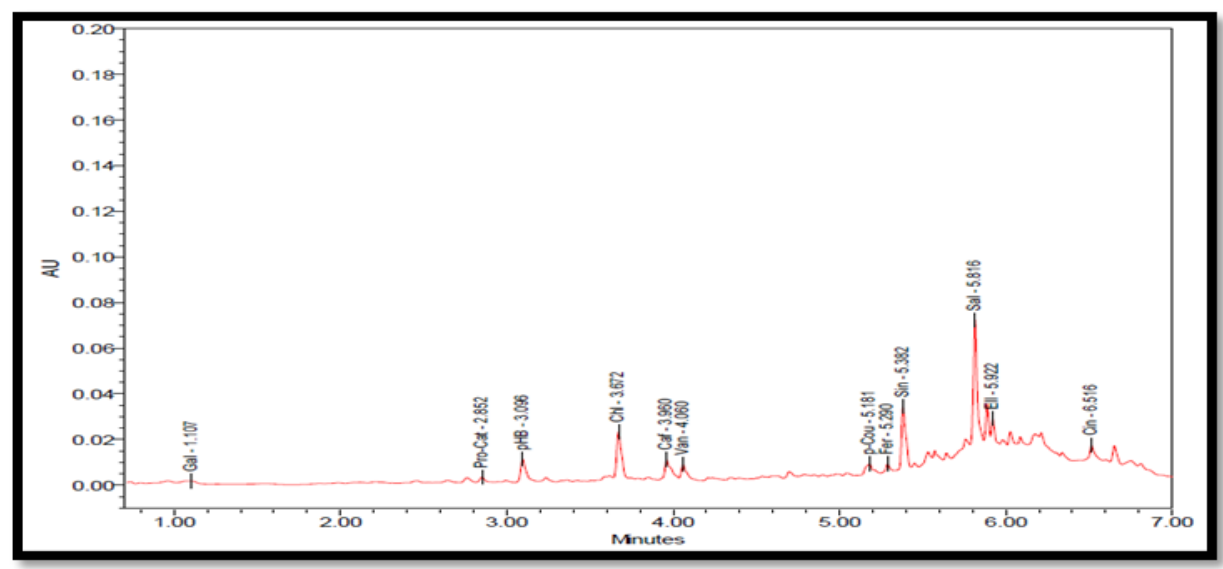

Fig.6 UPLC chromatogram of phenolic acid for $\mathrm{T}_{2}$ i.e. AT - 3 (Disease)

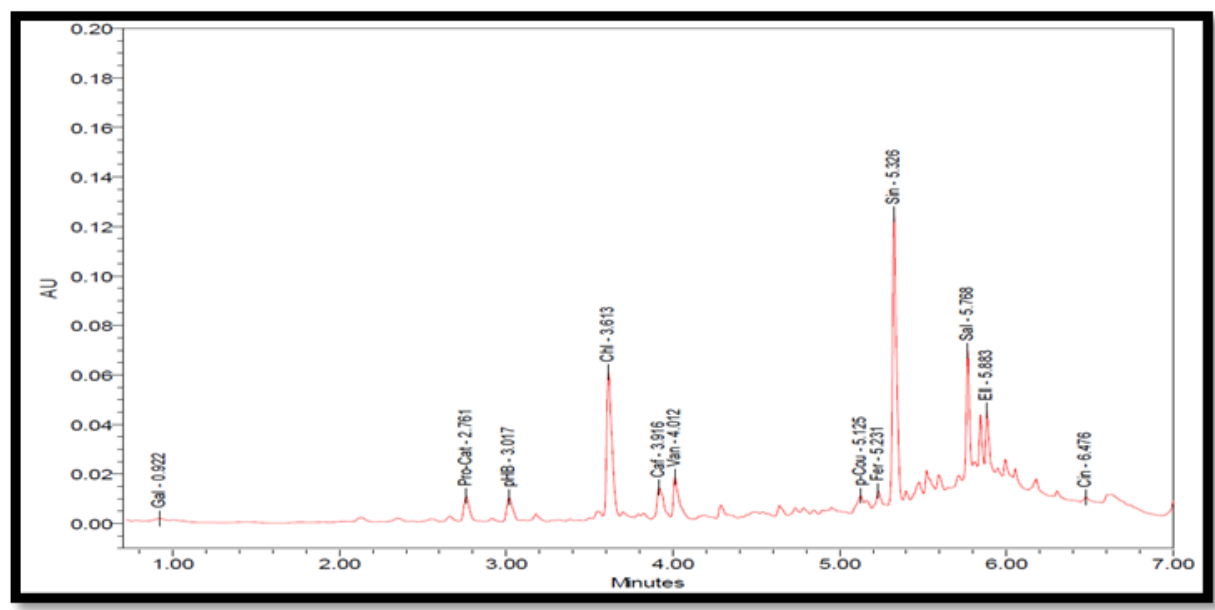


Fig.7 UPLC chromatogram of phenolic acid for $\mathrm{T}_{3}$ i.e. SL - 120 (Control)

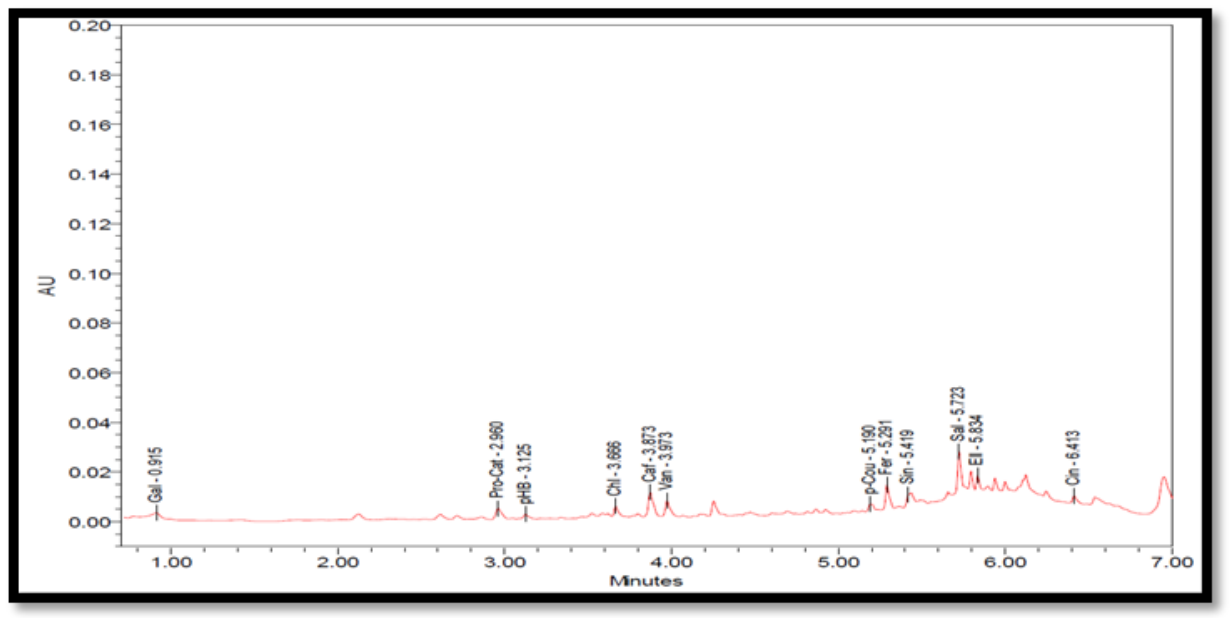

Fig.8 UPLC chromatogram of phenolic acid for $\mathrm{T}_{4}$ i.e. SL - 120 (Disease)

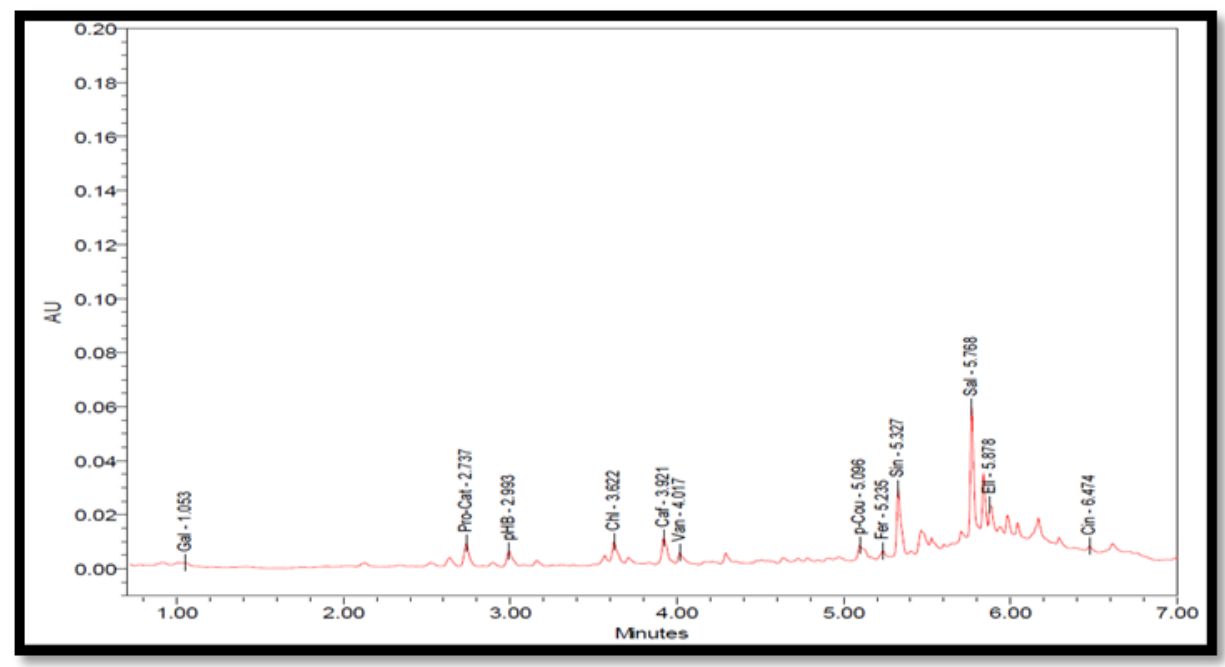

Phenolic profile of roots of both susceptible and resistant genotype under both disease and control conditions were analysed by UPLC, the chromatographic data are presented in Appendix I. The external standard method in which reference compounds were analysed under similar chromatographic conditions separately from samples was used for quantification purpose.

In the present study total twelve phenolic acids were identified and quantified in the resistant and susceptible cultivars under control and root knot disease conditions in tomato root. The results showed that the content and type of phenolic compounds varied depending on the condition (control and root knot disease) and type of cultivar (AT 3 and SL 120). UPLC analysis confirmed the presence of several phenolic acids in roots of tomato with all the treatments (Fig. 5, 6, 7 $\&$ 8). Sinapic acid content was ranged from $4.89-18.50(\mu \mathrm{g} / \mathrm{g} \mathrm{FW})$. It was found to be the highest $(18.50 \mu \mathrm{g} / \mathrm{g}$ FW) in AT 3 
(disease) i.e. $\mathrm{T}_{2}$ among the all root samples and found to be the one with higher 3.4 folds change from control to disease condition (Figure 3). While chlorogenic acid (15.84 $\mu \mathrm{g} /$ g FW) and ellagic acid (7.89 $\mu \mathrm{g} / \mathrm{g} \mathrm{FW})$ were the other phenolic acids after sinapic acid which were found to be increased significantly under root-knot biotic stress in susceptible cultivar AT 3 as compared to control condition (Fig. 3). Reverse trend was observed for ellagic acid and caffeic acid in resistant cultivar SL 120. Vanillic acid (4.69 $\mu \mathrm{g} / \mathrm{g}$ FW) had shown significant increased under root-knot biotic stress as compared to control condition (2.05 $\mathrm{\mu g} / \mathrm{g}$ FW) in susceptible cultivar AT 3. The non-significant difference was observed for $p$ hydroxybenzoic acid in susceptible cultivar AT 3 upon transition from control condition to disease condition. Salicylic acid was the only phenolic acid found to be increased the most (1.95 folds) during disease condition as compared to control in resistant cultivar SL 120 (13.96 $\mu \mathrm{g} / \mathrm{g}$ FW). p - coumaric acid and cinnamic acid did not differ much in their quantity between control and disease conditions in both the cultivars (Figure 3 ). These results were in agreement with the results obtained by Baker et al., (2010).

\section{References}

A. O. A. C. 2000. Association of Official Analytical chemists, 17th Ed. Official Methods of Analysis, Washington, DC, USA.

Abad, P., Gouzy, J., Aury, J. M., CastagnoneSereno, P., Danchin, E. G., Deleury, E., Perfus-Barbeoch, L., Anthouard, V., Artiguenave, F. and Blok, V. C. 2008. Genome sequence of the metazoan plant-parasitic nematode Meloidogyne incognita. Nature biotechnology, 26: 909-915.

Baker, C. J., Owens, R. A., Whitaker, B. D., Mock, N. M., Roberts, D. P., Deahl, K.
L., et al., 2010. Effect of viroid infection on the dynamics of phenolic metabolites in the apoplast of tomato leaves. Physiol. Mol. Plant Pathol. 74: $214 \quad-\quad 220 . \quad$ Doi: 10.1016/j.pmpp.2010.02.001.

Bird, D. M., and Kaloshian, I. 2003. Are roots special? Nematodes have their say. Physiological and Molecular Plant Pathology.62:115-123.

Bray, H. G., and Thorpe, W. V. 1954. Meth. Biochem. Anal., 1: 27-52.

Choudhary, K., Chawla, N., Kaur, S. and Jindal, S. 2013. Analysis of biochemical parameters in tomato fruits before and after inoculation with root knot nematode (Meloydogyne incognita). Vegetable Science, 40 (2): 178-181.

Dawson, P., and Weste, G. 1984. Impact of root infection by Phytophthora cinnamomi on the water relations of two Eucalyptus species that differ in susceptibility. Phytopathology, 74: 486490.

Giovanelli, G., and Paradise, A. 2002. Stability of dried and intermediate moisture tomato pulp during storage. Journal of Agriculture and Food Chemistry, 50: 7277-7281.

Hung, C. L., and Rohde, R. A. 1973. Phenol accumulation related to resistance in tomato to infection by root-knot and lesion nematodes. Journal of Nematology 5, 253-258.

Indian Horticulture database - 2014-15. National Horticulture Board, Ministry of Agriculture, Government of India. (NHB, 2016). Website: www.nhb.gov.in

Jain, R. K., Mathur, K. N. and Singh, R. V. 2007. Estimation of losses due to plant parasitic nematodes on different crops in India. Indian. J. Nematol., 37: 219220.

Krishnappa, K., 1985. Nematology in developing counties, India IMP region 
VIII, In: An Advanced Treatise on Meloidogyne, Vol. I- Biology and control (Sasser, J.N. and C.C. Carter eds.), A Coop. Publ. Dept. of Plant Pathology and USAID), North Carolina, Raleigh, U.S.A., 1: 379-398.

Mariutto, M., Duby, F., Adam, A., Bureau, C., Fauconnier, M. L., Ongena, M., Thonart, P. and Dommes, J. 2011. The elicitation of a systemic resistance by Pseudomonas putida BTP1 in tomato involves the stimulation of two lipoxygenase isoforms. BMC Plant Biology, 11: 29.

Patel, G. J., Patel, D. J., Jogani, D. K. and Patel, S. T. 1986. Wheat - a new host of Meloidogyne javanica in India. Indian J.
Nematol., 16: 134.

Prasad, S. K., 1960. Plant parasitic nematodes at Indian Agricultural Research Institute farm. Indian J. Entomol., 22: 127-128.

Shreenivasa, K. R., Krishnappa, K., and Rekha, D., 2011. Interaction effect of arbuscular mycorrhizal fungus, glomus fasciculatum and root knot nematode meloidogyne incognita on biochemical parameters in tomato. I. J. S. N., 2(3): 534-537.

Syeda, B. B., Muhammad, qba B. and Shahabuddin, M. 2008. Antioxidative activity of extract from Fenugreek seeds (Trigonella Foenum-graecum). Pakistan Journal of Analytical and Environmental Chemistry 9 (2).

\section{How to cite this article:}

Vyomesh S. Patel, Y.M. Shukla and Dhruve, J.J. 2017. Influence of Root Knot Nematode (Meloidogyne spp.) on Phenolic Acid Profile in Root of Tomato (Solanum lycopersicum L.). Int.J.Curr.Microbiol.App.Sci. 6(10): 840-848. doi: https://doi.org/10.20546/ijcmas.2017.610.100 